\title{
Nanostructures of ITO Thin Films Induced by Low Energy Ion Beam
}

\author{
Haifeng $\mathrm{WU}^{1, \mathrm{a}}$, Xiangdong JIANG ${ }^{2, \mathrm{~b}}$, Yixiong $\mathrm{ZENG}^{3, \mathrm{c}}$ and Jimin $\mathrm{WANG}^{4, \mathrm{~d}}$ \\ ${ }^{1234}$ School of Optoelectronic Information,University of Electronic Science and Technology of \\ China,Chengdu 610054,China \\ awuhaifenger@163.com, bxdjiang@uestc.edu.cn, ${ }^{c} 522625441 @$ qq.com and ${ }^{\mathrm{d}} 609437919 @$ qq.com
}

\begin{abstract}
This paper presents a novel method that using low energy hydrogen ion beam at normal incidence to deal with indium tin oxide(ITO) thin films. The surface structure of ITO thin films are controlled by changing parameters of ion source(IS),such as ion energy,ion beam current,substrate temperature and processing time.In this paper,the ion energy is set at $300 \mathrm{eV}$, the ion beam current ranges from $60 \mathrm{~mA}$ to $100 \mathrm{~mA}$, the substrates are heated to $120{ }^{\circ} \mathrm{C}$ and $150{ }^{\circ} \mathrm{C}$, the processing time is from $5 \mathrm{~min}$ to $25 \mathrm{~min}$. Setting the ion source parameter at $300 \mathrm{eV}, 120{ }^{\circ} \mathrm{C}$ and $60 \mathrm{~mA}$, with the growing of time, the nanoparticles(NPs) on the surface of ITO layer appears, and the diameter of nanoparticles is reduced as the treating time is beyond 15 min.In addition to,transforming the ion beam current from $80 \mathrm{~mA}$ to 100 $\mathrm{mA}$,other parameters,such as maintaining the ion energy at $300 \mathrm{eV}$, substrate temperature at $150{ }^{\circ} \mathrm{C}$ and conducting time at $15 \mathrm{~min}$, it demonstrates that the nanoparticles size of ITO layer is more uniform and dense nanostructures at $100 \mathrm{~mA}$ ion beam current than at $80 \mathrm{~mA}$ ion beam current.It means that altering the ion beam current could affect the nanoparticles size distribution and,furthermore,control the surface nanostructure of ITO layer.
\end{abstract}

\section{Introduction}

One Dimension(1D) nanomaterials show various electrical and optical properties[1,2] compared to their bulk materials.For instance,metallic NPs have quantum confinement effect,surface effect and tunneling effect when the particles diameter are confined 1 to 100 $\mathrm{nm}[3,4]$.Besides,metallic nanoparticles exhibit higher light absorption than their bulk counterpart due to surface plasma effects and form many nano-electrodes to increase efficient potential contact.ITO thin film[5] is one kind of transparent conducting oxide with high conductivity,high transmittance in visible light region and good chemical stability,it is regarded as a transparent electrode materials widely used in LCD,PDP,touch screen and solar cells[6,7].

Using hydrogen plasma[8,9] to handle ITO thin films in Plasma Enhanced Chemical Vapor Deposition(PECVD) has been reported in recent years.As our knowledge, using $\mathrm{Ar}^{+}$

* Corresponding author:xdjiang@uestc.edu.cn 
[10] or $\mathrm{Xe}^{+}[11]$ ion beam to treat the surface of $\mathrm{Si}, \mathrm{Ge}$ and $\mathrm{GaAs}$ has been reported in previous researches.However,it is seldom to see someone to utilize low energy hydrogen ion beam to treat ITO thin films. Unlike the principle of generating hydrogen plasma in PECVD, which needed high $\mathrm{H}_{2}$ flux and produced hydrogen plasma by means of an unaccelerated electrical field, the IS could not only produce high density of $\mathrm{H}^{+}$ions with specific direction and large ions momentum,but require smaller $\mathrm{H}_{2}$ flux than in PECVD.Apart from above advantages, the equipment charges of PECVD is more expensive than IS devices and it is not easy to maintain in comparison to IS equipment.

In this paper,the formation of nanostructure on ITO layer by employing IS to produce hydrogen ions to treat ITO thin films.Besides, the influence factor of surface nanostructures, such as ion beam current value or ion beam current density,substrate temperature,ion energy and processing time has been studied in details.

\section{Experimental Details}

The ITO thin films were deposited on the glass substrate, the thickness of ITO thin films were around $25 \mathrm{~nm}$ and the size were $15 \mathrm{~mm} \times 25 \mathrm{~mm}$. Subsequently, the glass substrates coated ITO thin films were cleaned by washing-up liquid for wiping off surface contaminants. Then,the substrates were cleaned by ultrasonic devices in the mingle solution of ethanol, $\mathrm{NaOH}$ and deionized(DI) water for $5 \mathrm{~min}$,Finally, the substrates was rinsed several times by DI water and blowed by $\mathrm{N}_{2}$. The cleaned ITO glass substrates were rapidly placed in the vacuum chamber,the reaction pressure was $2.5 \mathrm{E}-2 \mathrm{~Pa}$, the ion beam current changed from $60 \mathrm{~mA}$ to $100 \mathrm{~mA}$, the IS energy was $300 \mathrm{eV}$, the reaction time was increased from $5 \mathrm{~min}$ to $25 \mathrm{~min}$ and the substrates were heated to $120{ }^{\circ} \mathrm{C}$ and $150{ }^{\circ} \mathrm{C}$, the $\mathrm{H}_{2}$ flux maintained in $3.5 \mathrm{sccm}$.

The IS type was Kaufman IS(KFM-12), the max ion beam current of this IS was $150 \mathrm{~mA}$ and the max ion energy was $600 \mathrm{eV}$.The surface morphology of ITO thin films was detected by scanning electron microscope(FEI INSPECT F SEM).

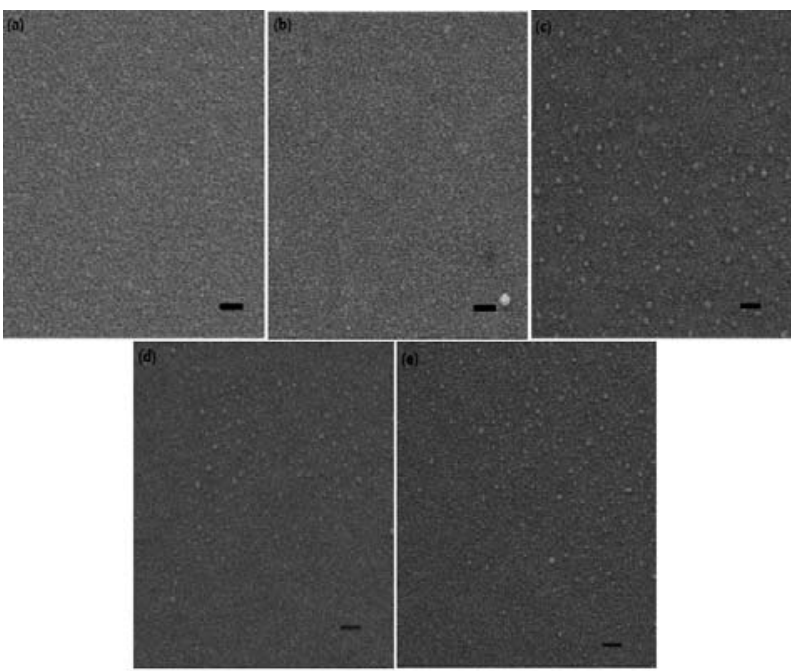

Fig. 1 SEM images of ITO thin films on glass substrate treated by hydrogen ions at $60 \mathrm{~mA}$ ion current beam, $120{ }^{\circ} \mathrm{C}$ substrate temperature, $300 \mathrm{eV}$ ion energy and different treating time, all scale bars $=200 \mathrm{~nm}$, (a) 5 min,(b)10 min,(c)15 min,(d)20 min, and (e)25 min. 


\section{Results and Discussion}

Fig. 1 shows SEM images of ITO thin films on glass substrates treated by hydrogen ions, the ion beam current is set at $60 \mathrm{~mA}$,the density of ion beam is around 0.531 $\mathrm{mA} / \mathrm{cm}^{2}$, the ion energy is $300 \mathrm{eV}$, and the processing time changes from 5 min to 25 min.With the growing of time,uniform distribution of NPs are emerged when processing time is beyond 15 min.Besides, the diameter of NPs is becoming smaller with the increase of treating time,the average diameter in Fig. 1(c),(d),(e) is respectively $\sim 50 \mathrm{~nm}, \sim 35 \mathrm{~nm}$ and $\sim 25 \mathrm{~nm}$. This phenomena is mainly due to the consisting hydrogen ions,especially $\mathrm{H}^{+}$ reduction[12,13] of ITO thin films. When the treating time is below $15 \mathrm{~min}$, the reduction reaction is not dominated, physical reaction,mainly is ion bombarding sputtering, plays an important role in the formation of surface nanostructure.Nevertheless, the mass of hydrogen ions is relatively smaller than oxygen atoms, and the momentum of hydrogen ions is so tiny that it could not bombard oxygen atoms effectively and peeling oxygen atoms off ITO thin films, thus not leading to formation of obvious nanostructures on the ITO thin films. When processing time exceeds 15 min,however,the reduction reaction acts as a major role,and the reducing capacity of $\mathrm{H}^{+}$is stronger than atom hydrogen[14], the ions beam contains numerous $\mathrm{H}^{+}$ions. Therefore, it is easily to obtain on NPs on the surface of ITO layer,and the diameter of NPs becomes smaller with the extension of time.As the treating time reach to $25 \mathrm{~min}$,the average diameter of ITO layer is the smallest one and the density of surface NPs is sparsest in all pictures of Fig. 1.

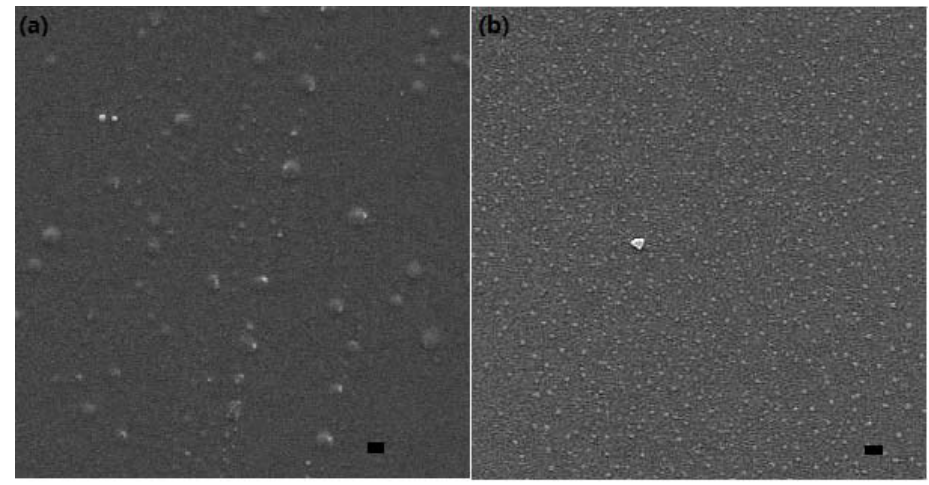

Fig. 2 SEM images of ITO thin films on glass substrates treated by hydrogen ion at $150{ }^{\circ} \mathrm{C}$ substrate temperature, $300 \mathrm{eV}$ ion energy and different ion current beam, all scale bars $=200 \mathrm{~nm}$, (a) $80 \mathrm{~mA}, 15 \mathrm{~min}$ and (b) 100 $\mathrm{mA}, 15 \mathrm{~min}$

Fig. 2 displays SEM images of ITO thin films treated by hydrogen ion at $300 \mathrm{eV}$ of ion energy, $150{ }^{\circ} \mathrm{C}$ of substrate temperature, $15 \mathrm{~min}$ of handling time and different ion beam current,the ion beam current in Fig. 2(a) is $80 \mathrm{~mA}$ and in Fig2(b) is $100 \mathrm{~mA}$,respectively,the density of ion beam current in Fig. 2(a) is $0.707 \mathrm{~mA} / \mathrm{cm}^{2}$ and in Fig2(b) is 0.884 $\mathrm{mA} / \mathrm{cm}^{2}$.the obtainment of surface nanostructures in Fig. 2(b) is more uniform size and intensive surface density than in Fig. 2(a).It indicates that the size of surface nanostructure depends on the density of ion beam current. The ion beam current somewhat represents the concentration of hydrogen ions.Accompanied with high hydrogen ions concentration,the reduction effect of ITO thin films is good.It has been demonstrated in Fig. 2 that much denser and smaller NPs at $100 \mathrm{~mA}$ ion beam current in Fig. 2(b) than at $80 \mathrm{~mA}$ ion beam current in Fig. 2(a). Meanwhile,the reacting time selects to $15 \mathrm{~min}$ because of optimized reducing effect of ITO thin films and good distribution of NPs in Fig. 1. 


\section{Conclusion}

In this study,the homogeneous NPs distribution on the surface of ITO thin films were obtained successfully via utilizing low energy IS.The suitable treating time of hydrogen ions is $15 \mathrm{~min}$ as well as ion beam current at $60 \mathrm{~mA}$. When treating time is less than 15 min,any evident nanostructures could not observed on the surface of ITO thin films. On the contrary,sparse and symmetrical NPs distribution is on ITO layer.The best treating time at $60 \mathrm{~mA}$ is distinct at $15 \mathrm{~min}$. With the growing of ion beam current and substrate temperature, the more uniform distribution and smaller size of NPs acquired at $100 \mathrm{~mA}$ ion beam current,thus the best experiment parameter of getting well-organized dots nanostructures is setting the ion beam current at $100 \mathrm{~mA}$ and the substrate temperature at $150{ }^{\circ} \mathrm{C}$ in our study.However,altering other parameters,such as ion energy and substrate temperature remains to be studied further.

\section{Acknowledgments}

This research was funded by the National Science Foundation of China (NSFC) (Grant No. 51372032).

\section{References}

1. X.D.Xu, S.B.Li, Y.C.Wang, et al, Silicon nanowires prepared by electron beam evaporation in ultrahigh vacuum, Nanoscale.Res.Lett. 243(2012)1-7.

2. J.V.Wittemann,W.Münchgesang,S.Senzetc, Silver catalyzed ultrathin silicon nanowires grown by low-temperature chemical-vapor-deposition,J.Appl.Phys. 107(2010)096105.1-3.

3. Ball P, Science at the atomic scale, J.Nature. 355(1992)761-767.Ulyashin, A.Sytchkova, Hydrogen related phenomena at the ITO/a-Si:H/Si heterojunction solar cell interfaces, Phys. Status. Solidi. A. 210(2013)711-716.

4. G.O. Setti, M.B. Mamián-López ,P. R. Pessoa,et al, Sputtered gold-coated ITO nanowires by alternating depositions from Indium and ITO targets for application in surface-enhanced Raman scattering, Appl.Surf.Sci. 347(2015)17-22.

5. R.Savu,E.Joanni, Effect of processing conditions on the nucleation and growth of indium-tin-oxide nanowires made by pulsed laser ablation, J. Mater. Sci. 43(2008) 609-613.

6. W.C.Chang,C.H.Kuo,P.J.Lee,Y,et al, Synthesis of single crystal Sn-doped $\mathrm{In}_{2} \mathrm{O}_{3}$ nanowires:size-dependent conductive characteristics, Phys.Chem.Chem.Phys. 14(2012) 13041-13045.

7. B.S.Swain,S.S.Lee,S.H.Lee, et al, Transformation of silicon nanowires to nanocoils by annealing in reducing atmosphere, J.Cryst.Growth. 327(2011)276-280.

8. B.S.Swain,S.S. Lee,S.H.Lee,et al, Effect of H2 ambient annealing on silicon nanowires prepared by atmospheric pressure chemical vapor deposition, Chem. Phys.Lett. 494(2010)269-273.

9. R.Gago,L.Vázquez,R.Cuerno,et al, Production of ordered silicon nanocrystals by low-energy ion sputtering, Appl.Phys.Lett. 78(2001)3316-3318.

10. B.Ziberi,F. Frost,B.Rauschenbach, Formation of large-area nanostructures on Si and Ge surfaces during low energy ion beam erosion,J. Vac. Sci. Technol. A.24(2006)1344-1348.Kuboi, Degradation of ITO Film in Glow-Discharge Plasma, Jpn.J.Appl.Phys. 20(1981)783-786.

11. M.Jeon,K.Kamisako, Catalyst formation at various temperatures by hydrogen radical treatment and synthesis of silicon nanowires , Appl.Surf.Sci.

12. 254(2008)7703-7707. R.A.Palmer,T.M.Doan,P.G.Lloyd,et al, Reduction of $\mathrm{TiO} 2$ with Hydrogen Plasma, Plasma.Chem.Plasma.P. 22(2002)335-350. 